\title{
A MULTIDISCIPLINARY ANALYTICAL FRAMEWORK FOR STUDYING ACTIVE MOBILITY PATTERNS
}

\author{
D. Orellana ${ }^{\mathrm{a}, \mathrm{b}} *$, C. Hermida ${ }^{\mathrm{c}}$, P. Osorio ${ }^{\mathrm{a}}$ \\ ${ }^{\text {a }}$ LlactaLAB CIudades Sustentables. Departamento de Espacio y Población. Universidad de Cuenca, Av. 12 de Abril, Cuenca, \\ Ecuador - daniel.orellana@ucuenca.edu.ec, pablosorio@gmail.com \\ ${ }^{\mathrm{b}}$ Facultad de Ciencias Agropecuarias. Universidad de Cuenca, Av. 12 de Octubre, Cuenca, Ecuador. \\ ${ }^{\mathrm{c}}$ Escuela de Arquitectura, Universidad del Azuay, Av. 24 de Mayo, Cuenca, Ecuador. - chermida@uazuay.edu.ec
}

\section{Commission II, WG II/8}

KEY WORDS: Active mobility, Movement Analysis, Spatial Behaviour, Sustainable Cities

\begin{abstract}
:
Intermediate cities are urged to change and adapt their mobility systems from a high energy-demanding motorized model to a sustainable low-motorized model. In order to accomplish such a model, city administrations need to better understand active mobility patterns and their links to socio-demographic and cultural aspects of the population. During the last decade, researchers have demonstrated the potential of geo-location technologies and mobile devices to gather massive amounts of data for mobility studies. However, the analysis and interpretation of this data has been carried out by specialized research groups with relatively narrow approaches from different disciplines. Consequently, broader questions remain less explored, mainly those relating to spatial behaviour of individuals and populations with their geographic environment and the motivations and perceptions shaping such behaviour. Understanding sustainable mobility and exploring new research paths require an interdisciplinary approach given the complex nature of mobility systems and their social, economic and environmental impacts. Here, we introduce the elements for a multidisciplinary analytical framework for studying active mobility patterns comprised of three components: a) Methodological, b) Behavioural, and c) Perceptual. We demonstrate the applicability of the framework by analysing mobility patterns of cyclists and pedestrians in an intermediate city integrating a range of techniques, including: GPS tracking, spatial analysis, auto-ethnography, and perceptual mapping. The results demonstrated the existence of non-evident spatial behaviours and how perceptual features affect mobility. This knowledge is useful for developing policies and practices for sustainable mobility planning.
\end{abstract}

\section{INTRODUCTION}

Intermediate cities are facing complex challenges at the beginning of XXI century, which includes changing and adapting their mobility systems from a high energy-demanding motorized model to a sustainable low-motorized model. Promoting pedestrian and bicycle mobility is a cost-effective way to dramatically reduce environmental and socioeconomical impacts derived from the car-based transportation model and improve the population's wellbeing.

In fact, active mobility (also known as non-motorized mobility) plays a key role in both developing efficient and equitable transportation systems and in moving towards more sustainable cities. Non-motorized modes are resource-efficient since they require less infrastructure (i.e. roads and parking space) and pose minimal costs for users, administrations and the environment. Additionally, they can be easily integrated into the public transit systems providing versatile mobility access for everyone including: youth, senior citizens, people with disabilities or special needs and the economically disadvantaged that otherwise would struggle to travel independently. Beyond efficiency and equality, these modes offer a fun and healthy way to move within the urban environment and help to create more liveable communities and encourage efficient development (Victoria Transport Policy Institute, 2016).

In order to accomplish a low-motorized transportation model, city administrations need to better understand how, where, why and who moves around the city. Collecting, analysing and

\footnotetext{
*Corresponding author
}

interpreting mobility patterns and their links to demographic, socio-economic, cultural and psychological aspects of the individuals and groups are therefore a fundamental step in planning and implementing sustainable mobility policies.

During the last decade, researchers have demonstrated the potential of geo-location technologies and mobile devices to gather massive amounts of data for mobility studies. The analysis and interpretation of this data has been carried out by specialized research groups from different disciplines such as: spatial analysis, data-mining, spatial statistics, transportation engineering, urbanism, social psychology, among others, and have focused primarily on movement data collection techniques (Feng and Timmermans, 2014; G. Griffin and Jiao, n.d.; Quiroga, Romero, García, and Parra, 2011; Sayed, Zaki, and Autey, 2013; Zaki and Sayed, 2013) and data structures for efficient storage and movement data retrieval (Forlizzi, Güting, Nardelli, and Schneider, 2000; Güting and Schneider, 2005; Tryfona and Jensen, 1999). Other studies have developed datamining algorithms and visual analytic techniques to detect and extract movement patterns from massive geo-location datasets (Andrienko and Andrienko, 2008; Gudmundsson, Laube, and Wolle, 2007; Laube, 2009; Orellana and Wachowicz, 2011; Thomas and Cook, 2006; Thomason, Griffiths, and Sanchez, 2015), and methods for enriching movement data with semantics (Alvares et al., 2007; Baglioni, Macedo, Renso, Trasarti, and Wachowicz, 2009; Bogorny, Heuser, and Alvares, 2010).

Although fruitful, these efforts have been focused on narrow aspects of mobility. Consequently, broader questions remain unanswered, mainly those relating spatial behaviour of individuals and populations within their geographic 
environment and the motivations and perceptions shaping such behaviour. In order to advance the knowledge of sustainable mobility and to explore new research paths, interdisciplinary approaches are needed. In fact, researchers are showing increased interest in such interdisciplinary approaches, where the use, adaptation and combination of methods and techniques from different disciplines enable them broaden the scope of their research and explore the interactions of different elements of urban mobility.

Conducting interdisciplinary research is challenging due to difficulties integrating different approaches, methods and interpretations of disciplinary frameworks that researchers use in each field. Consequently, new frameworks are needed to allow specialists to collaborate and communicate while exploring and understanding the complexity of urban mobility.

In an effort to contribute to this need, here we present three elements for an analytical framework to study patterns of nonmotorized urban mobility: a) Methodological, b) Behavioural, and c) Perceptual. The first component (Methodological) attempts to adapt, develop and combine methods and techniques, looking for a cross-disciplinary synergy that allows a better understanding of mobility patterns. The second component (Behavioural) aims to explore and understand the relationship between the spatial behaviour of people and the environment in which they move. The third component (Perceptual) studies the effect that mobility has upon the perception of environment. The proposed framework is the result of an on-going discussion among researchers from geography, architecture, urbanism, environmental studies, psychology, and computer sciences.

In this study we provide context for the proposed framework through literature, theory and practice. The remaining of this document is structured as follows: Section 2 details the main assumptions and elements in which the proposed framework is based. Section 3 discusses the three key components of the framework based on relevant literature. Section 4 presents an application of the framework to study the spatial behaviour of pedestrians and bicycle users in the city of Cuenca, Ecuador. Finally, Section 5 outlines the main conclusions and outline next steps of this research.

\section{MAIN ASSUMPTIONS AND ELEMENTS}

\subsection{Main assumptions}

In the process of developing the proposed framework, some assumptions were made in order to frame our proposal. These assumptions are usually accepted among researchers although not always in an explicit way. Here we list these assumptions in order to provide a clear context for the analytical framework.

Movement is a key aspect of spatial behaviour, and is the result of people interacting with each other and their spatial environment (Orellana and Renso, 2010). Therefore space is more than a static background in which people move, but an active element of movement behaviour (Hillier, 2007). In other words, space has agency in the sense that it influences and is influenced by movement.

Movement is a dynamic complex system and therefore exhibits some key features such as: feedback loops, selfadaptation, emergent patterns, non-linearity, sudden transitions and tipping points (Mayer-Kress, Liu, and Newell, 2006).
Movement is ruled by limitations, "and not by independent decisions by spatially or temporally autonomous individuals" These limitations include capability, coupling, and authority restrictions (Hägerstrand, 1970).

Movement patterns are the evidence of spatial interactions, and therefore we can understand important aspects of people's mobility by studying the structures of spatio-temporal footprints of individuals as they move. In this sense, a movement pattern is a high-level description of how the movement of an individual or group relates to the underlying space (Laube, 2009).

Movement behaviour is determined by a hierarchic structure of decision-making at three levels: (i) A strategic level in which the individual decides their destination, activities and aims, (ii) a tactical level in which the individual decides the route to follow, the places to avoid, and reactions to unexpected events; and (iii) an operational level in which he/she decides the next step, which means that they intuitively choose a direction and speed, depending on the immediate environment (Hoogendoorn and Bovy, 2004).

Active mobility is fundamentally different from motorized mobility and usually underestimated. Although obvious at first glance, this differentiation must be explicit when studying movement and spatial behaviour of people. Interactions, restrictions, motivations, perceptions and strategies are different when individuals move within a motorized vehicle than when they walk or bike. Current practices tend to undercount shorter trips, non-work trips, off-peak trips, non-motorized links of motorized trips, travel by children, and recreational travel. As a result, there are usually far more non-motorized trips than what conventional travel models recognize (Victoria Transport Policy Institute, 2016).

\subsection{Main elements}

Based on these assumptions we propose an analytical framework for the study of non-motorized urban mobility patterns. The proposed framework involves three components: (i) methodological, (ii) behavioural, and (iii) perceptual. Each component attempts to address a common challenge on active mobility studies.

The methodological component attempts to explore, evaluate and combine methods and techniques from different disciplines. The premise for this component is that the synergy of methods from different fields boosts the analytical possibilities for the framework. Several methodological approaches are explored for main phases of the research: data collection, analysis, and interpretation.

The behavioural component aims to understand the effect of the environment on the spatial behaviour of people as they move. Revisiting the assumption of space as an active agent of the movement phenomena, this component explores the variables of urban space that trigger and modify different behaviours at the three decision-making levels mentioned above.

The perceptual component focuses on understanding how movement affects the perception of urban environments, and therefore influences people's feelings and opinions. There are obvious links between the perceptual and behavioural components in terms that one influence each other and this highlights the feedback loops mentioned in the assumptions. 
Each component, however, focuses on a different set of research questions.

\section{COMPONENTS OF THE FRAMWEORK}

\subsection{Methodological component}

Among the main challenges for a better understanding of active mobility, is to select and combine methods and techniques from different disciplines. This component of the framework attempts to answer the question "How to collect, store, analyse and interpret data for exploring and understanding active mobility?" Although this question usually appears later in a scientific research, we want to start with this component to highlight the diversity of fields involved on studying mobility.

Traditionally, movement data collection was carried out using two main methods: individual-oriented and place-oriented. Individual-oriented methods mainly consisted of transportation and mobility surveys that include home and work/study locations and main transportation modes. Place-oriented methods mainly consisted of counting people and vehicles passing through a checkpoint using manual or automatic techniques. These two approaches together were most commonly used for mobility studies with the disadvantage of high costs and lack of detailed information (Golob and Meurs, 1986).

Nowadays, scientists, practitioners and planners recognise the huge potential of massive geo-location data produced by the confluence of ICTs and geo-positioning technologies. Dedicated location devices such as GPS are widely used for mobility and transportation studies thanks to its high spatial and temporal resolution and low cost. Researchers have studied mobility patterns simply by giving GPS devices to groups of people for a period of time and analysing the locations, times and routes recorded by the devices.

Although simple and powerful, this approach has limitations regarding the low number of people that can be reached in each study and the battery/memory limitations of the devices. Therefore, researchers have investigated other ways to collect movement data from geo-enabled devices such as smartphones, tablets or wearable computers; including developing and implementing dedicated monitoring apps. It is now common for companies and corporations to offer Location Based Services (LBSs) in exchange for user's location data, some times in a rather obscure way or without full acknowledgment from the user. The usefulness of this approach has been proved through services such as Google Maps' traffic layer (Google, 2016) and Strava METRO or Waze's navigation services (Waze Mobile, 2016). Also, researchers have shown that it is possible to extract movement information from social networks data (Dunkel, 2015; G. P. Griffin and Jiao, 2015; Torres and Costa, 2014). In a more participatory way, crowdsourcing and volunteer geoinformation approaches can be of great interest for researchers. People who are interested in improving mobility in the cities can participate by donating their geo-location data for research and planning using web-based or mobile apps to collect and store data. Ludic approaches can engage users and add value to the use of such applications (Capos SpA, 2015).

The vast amount of movement data being collected by the aforementioned approaches poses new challenges for researchers in storing, organising and analysing these massive datasets. During the last decade, researchers from computer science have developed data models and structures for efficient storage and retrieval (Forlizzi et al., 2000; Güting and Schneider, 2005; Tryfona and Jensen, 1999). Extracting information from these massive datasets is also important. Scientists are developing data-mining algorithms to detect and extract movement patterns (Gudmundsson et al., 2007; Laube, 2009), and applying visual analytics approaches to explore and understand those movement patterns (Andrienko and Andrienko, 2008; Thomas and Cook, 2006). Other researchers are interested in extracting significant locations from movement data (Thomason et al., 2015), exploring the spatial properties of movement data such as spatial autocorrelation (Orellana and Wachowicz, 2011), or enriching movement data with semantics (Alvares et al., 2007; Baglioni et al., 2009; Bogorny et al., 2010).

Although technology-based techniques gained huge attention during the last years, some field-based methods are still irreplaceable since they provide direct contact with the reality and offer a deeper understanding of the phenomena. Therefore, methods such as ethnographies (Lugo, 2013; Meneses-Reyes, 2013), in-deep interviews and direct observation (Jirón, 2011), and other approaches from sociology (Jungnickel and Aldred, 2014) not only remain popular among social scientists but they are gaining a renewed impetus even among researchers from engineering, architecture or computer sciences who are rediscovering the opportunities these approaches offer.

It is arguable that the most interesting research opportunities are located at the intersection of the different approaches. For example, digital video with action cameras can be used to study in detail the sensorial experience of riding a bicycle around the city (Spinney, 2011). In another example, mobile ethnography in combination with geo-location devices have been used in Utrech to study the embodied experience of cycling (Duppen and Spierings, 2013). Likewise the UWAC project at UK adopted a hybrid methodology by administrating surveys and interviews to households and individuals as well as ethnographic observation during a year in combination with spatial analysis techniques (T. Jones et al., 2012).

\subsection{Behavioural component}

A large amount of research has been conducted on how, when and why people decide to move around the city. In the context of the proposed framework we organise these findings on the hierarchical decision-making structure mentioned on the assumptions. Hereby, we briefly mention some examples of how the urban environment influences human movement behaviour based on the three tiers: strategic, tactical and operational.

Strategic level refers to decisions made in relation to destination, activities, aims, and the mode of the trip, and consequently, the use of motorized or non-motorized mobility. Influence of the urban environment at the strategic level includes both physical and non-physical factors.

Based on a utility maximisation assumption, distance is the most mentioned factor for mobility planning, and it is frequently assumed that non-motorized modes are preferred for short trips. This idea, however, is not supported by evidence. In a preliminary study, the authors found no correlation between commuting distance and mode selection, which is consistent with previous research on several cities in England ( $\mathrm{T}$. Jones et al., 2012). Researchers have explored other factors affecting the strategic level, including culture (Mehta, 2008), accessibility, safety and comfort (Alfonzo, Boarnet, Day, Mcmillan, and 
Anderson, 2006; Talavera-Garcia and Soria-Lara, 2015; Weinstein Agrawal, Schlossberg, and Irvin, 2008), topography (Heinen, van Wee, and Maat, 2010; Iseki and Tingstrom, 2014; Rodríguez and Joo, 2004) and availability and closeness to transportation infrastructure (Cervero, Sarmiento, Jacoby, Gomez, and Neiman, 2009; Handy and Xing, 2011a; Khan, Kockelman, and Xiong, 2014).

Tactical level refers to decisions regarding routing, areas of preference/avoidance and activity scheduling. In other words, once the individual has decided where and how to go, they must decide the route to follow taking into account the places they need to visit, the timing and the preferred characteristics of the areas to cross.

At this level, network connectivity is the first variable taken into account (Handy and Xing, 2011b; Heinen et al., 2010; Khan et al., 2014). Routing is also influenced by the physical and visual continuity (Manum and Nordstrom, 2013; Rybarczyk and Wu, 2010), including obstacles, which are decisive mainly for the elderly (Alfonzo et al., 2006; Bernhoft and Carstensen, 2008). Moreover, it has been found that angular minimization is an important factor in route choice and that measurement of least angle routes in urban environments can be a useful way of predicting cyclist volumes (Raford, Chiaradia, and Gil, 2007).

Safety, in terms of crime and traffic accident, is also one of the aspects influencing the tactical level (Alfonzo, 2005), shaping the routes to avoid insecure areas. However, the importance of safety versus distance / time optimization is not yet well understood, since empirical evidence shows that on several cases, protecting infrastructure is underused. On the other hand, safety is highly dependent on perception, which will be analysed on the third component.

Finally, other components of environment that affects movement behaviour at the tactical level include population density, connectivity, and land use mixture (Cervero et al., 2009; Handy and Xing, 2011a; Khan et al., 2014). Higher density, greater connectivity, and more land use mix streets report higher rates of walking and cycling than low-density, poorly connected, and single land use streets (Saelens, Sallis, and Frank, 2003).

Operational level regards to the "next step", meaning that people will tend to follow the planned route but will change direction and speed in reaction to the changing, immediate environment, such as unpredicted obstacles and most notably the interactions with other individuals. It is clear that this level is highly unpredictable given the dynamic nature of the factors affecting it. Nevertheless, important research has been conducted on the operational level of movement, mainly focused on interactions among individuals, collectives and the environment, demonstrating that it is possible to detect, extract and replicate different kinds of movement patterns such as flocking, following, avoidance, among others (Gudmundsson et al., 2007).

It is worth mentioning that the set of decisions at the operational level might change decisions at the tactical level. For example, if a given street is found too crowded or insecure, the individual might decide to turn back or select a different route. On the other hand, the accumulated experience of decisions at the operational level will have an effect on tactical and strategic levels: For example, a cyclist who repeatedly enounters problems or obstacles on his/her preferred route will probably change to another route or even change their transportation mode.

Also, the three-tier system presented here is not the only way to organize the decision-making process for human mobility. As an example, Wiener, Büchner, \& Hölscher (Wiener, Büchner, and Hölscher, 2009) proposed a different approach based on the cognitive processes involved and the level of spatial knowledge that is available to the individual.

In the context of the analytical framework, the behavioural component allows researchers to organise research questions regarding the level in which people operate. It also explores the influence of decisions made at one level influence the other levels.

\subsection{Perceptual component}

People cycling or walking perceive the city in a different way than drivers or public transport commuters, since these modes offer a unique set of experiences of the urban landscape involving different sensorial channels, which are partially or totally blocked inside a motor vehicle. Although some researchers have investigated these differences, usually they have not been incorporated with other aspects of active mobility on policies or planning. Perceptions are determinant when deciding the transportation mode, but these are not usually addressed by conventional mode choice studies (Heinen et al., 2010)

In the proposed framework, perceptions are explicitly included since they shape motivations and spatial behaviour at different levels. In this context, the perceptual component includes not only sensorial stimuli but also explores the interpretation of such stimuli in the light of individual and collective experiences. We organize the perceptual component in three categories: perceptions about the environment, perceptions about other people and perceptions about the self.

Perceptions about the environment are largely affected by the mode of transportation. Cyclists and pedestrians interact directly i.e. without barriers with their environment, and are therefore more sensitive to the sights, sounds and smells of their surroundings. This can provide a rich experience but can also be overwhelming in the complex urban everyday life (Jungnickel and Aldred, 2014). The changes in perceptions of the urban environment when cycling has been studied using ethnographic methods, which allow a deeper understanding of such changes (P. Jones, 2005).

Several factors have been explored related to perceptions when walking and cycling. For example, researchers have identified which elements make a street to be perceived as "walkable", including density and mixture of uses, infrastructure, presence of other walkers, speed, illumination, among others (Wood, Frank, and Giles-Corti, 2010). Other studies have explored the perceptions of shared spaces in contrast to segregated pedestrian and bike lanes, indicating that pedestrians feel most comfortable in shared space under conditions which ensure their presence is clear to other road users - these conditions include low vehicular traffic, high pedestrian traffic, good lighting and pedestrian-only facilities. Conversely, the presence of many pedestrians and, in particular, children and elderly, makes drivers feel uneasy and, therefore, enhances their alertness. (Kaparias, Bell, Miri, Chan, and Mount, 2012). Age and gender also affects such perceptions. For example, older people tend to 
appreciate pedestrian and cycling facilities more than the young (Bernhoft and Carstensen, 2008).

Recent studies provided interesting insights on the influence of perception in choosing routes. For example Quercia, Schifanella, \& Aiello (2014) explored how three subjective attributes of urban environment happiness, quietness, and beauty can be crowd-sourced to inform an algorithm to recommend routes that are not only short but also emotionally pleasant.

Perceptions about the others are also affected by movement. Wood et al. (2010) studied how walking behaviour and neighbourhood characteristics can influence the sense of community, this is, 'a feeling that members have of belonging and being important to each other and a shared faith that members' needs will be met by the commitment to be together' (McMillan and Chavis, 1986). The results suggest that only certain kinds of walking (i.e. leisure and slow walking) may increase sense of community.

Perception about others also shapes movement behaviour. For example, pedestrians are more likely to engage in risky behaviours such as crossing a busy intersection if they see other pedestrians engaging in the same risky behaviour (Barrero et al., 2013).

Perceptions about the self are also affected by the practice of cycling and walking. On the one hand, car ownership in certain cultures has been related to a self-perception of economical and social success. This tendency may be changing in the last decade, when health and environmental concerns are broadly shared by new generations. Walking and cycling, therefore, contribute to shape an image of "responsible citizenship". For example, participants in a study portrayed cycling as a practice of independence and interdependence, "its mix of benefits for the individual and the collective make it an appropriate response to contemporary social problems" (Aldred, 2010). At the same time, cyclers and walkers, mainly those who recently changed from other motorized modes of transportations may be more self-aware regarding their physical skills and capabilities (P. Jones, 2005).

Cycling has also been related to identity building. In fact, transport-related identities exist in interplay with other social identities (Skinner and Rosen, 2007), but have their own implications: appeals to 'cyclists' seek to shape such identities (Aldred, 2013). These identities may vary depending on the socio-cultural context and even on the comparative frequency to other mobility modes. In cities where bicycles are integral part of the mobility, a 'cyclist' identity is less relevant, whereas in motor-dominated cities this identity is more salient and many times stigmatised (Green, Steinbach, Datta, and Edwards, 2010).

\section{APPLICATION}

To demonstrate the applicability of the proposed framework, we implemented it in an on-going research project to study active mobility patterns in the city of Cuenca, Ecuador. The aim of the project is to gain understanding on the spatial behaviour of pedestrians and cyclists in order to provide insights for the design and implementation of sustainable mobility public policies.
The framework helped to organise the research questions and methodology in a clear and direct way, and provided a common playfield for geographers, computer scientists, architects, and psychologists. Table 1 summarizes the main research questions and corresponding methodologies organized by components of the framework.

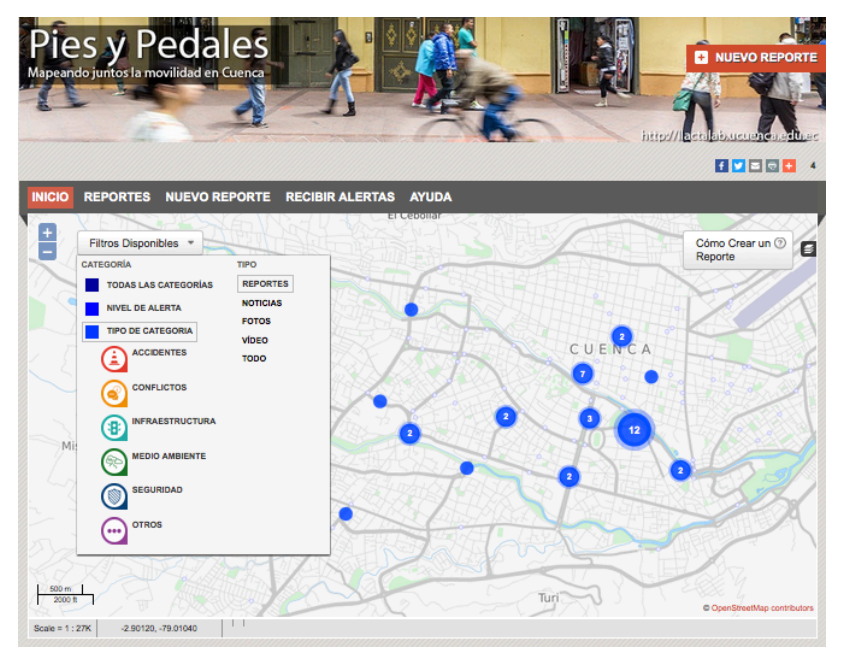

Figure 1: Platform for collaborative mapping of mobility. Source: http://piespedales.crowdmap.org

Although on early stages, the project is producing interesting results, which are being interpreted based on the different components of the framework. For example, we have created a collaborative mapping platform that allows any user to report mobility problems in the city using an interactive map, which allows mapping the perceptions about safety, conflicts and infrastructure (Figure 1). The results are compiled and analysed using spatial analysis techniques to compare with movement data collected with GPS data loggers carried by bicyclists. The project also created a citizen-science oriented initiative named "Scientists on Pedals" which invited people to participate in different stages of the project. The initiative has been well received and approximately 300 volunteers are currently participating. Other study in the project includes "controlled experiments" where volunteers are assigned to visit different checkpoints in the city. This allows analysing way-finding and routing behaviour of participants in relation with the urban environment. Finally, observational studies on the influence of physical and spatial variables on pedestrian flows are being conducted involving direct observation and automatic counting.

It is worth noting that although proposed methods are broadly used in the research field of mobility, it is the synergy among them, which allows a deeper exploration of the research questions.

\section{CONCLUSIONS}

In this paper, we introduced an analytical framework for the study of active mobility patterns in urban areas. The framework is based on a set of well-established assumptions regarding human movement and some elements that represent common questions in mobility research. The framework helps to organise multidisciplinary research efforts on active mobility by providing a structure for research questions and methodologies. The applicability is demonstrated in the context of an on-going research project, which aims to study the movement patterns of walking and cycling in Cuenca, Ecuador. 


\begin{tabular}{|c|c|c|}
\hline Research question & $\begin{array}{c}\text { Components } \\
\text { involved }\end{array}$ & Methods and techniques \\
\hline \multirow{3}{*}{$\begin{array}{l}\text { What are the differences } \\
\text { between optimal and actual } \\
\text { routes followed by } \\
\text { cyclists? }\end{array}$} & Methodological & $\begin{array}{l}\text { Data collection: GPS tracking, structured interviews, public space collaborative } \\
\text { mapping. } \\
\text { Analysis: Route optimization with impedances, geographical weighted regression }\end{array}$ \\
\hline & Behavioural & $\begin{array}{l}\text { Urban space features affecting the behaviour of cyclists: cycling infrastructure, } \\
\text { land use mixture and diversity, street network features, connectivity and spatial } \\
\text { syntax measures }\end{array}$ \\
\hline & Perceptual & Route qualification using subjective perceived attributes: safety, beauty, conflicts. \\
\hline \multirow[t]{3}{*}{$\begin{array}{l}\text { How do pedestrian flows } \\
\text { correlate to physical } \\
\text { attributes of urban space? }\end{array}$} & Methodological & $\begin{array}{l}\text { Data collection: field counts, street characterization, direct observation. Crowd- } \\
\text { sourcing mapping of mobility problems. } \\
\text { Analysis: geographical weighted regression. }\end{array}$ \\
\hline & Behavioural & $\begin{array}{l}\text { Street features affecting walkability: sidewalks, obstacles, blind walls, lighting, } \\
\text { services, land use, population density. } \\
\text { Spatial configuration: street proportions, connectivity, local and global } \\
\text { integration. }\end{array}$ \\
\hline & Perceptual & Perceived conflicts and attitudes. \\
\hline \multirow[t]{3}{*}{$\begin{array}{l}\text { Does proximity to daily } \\
\text { activities play a role in } \\
\text { mode-choice? }\end{array}$} & Methodological & $\begin{array}{l}\text { Data collection: survey on households, secondary sources on urban services and } \\
\text { activities. } \\
\text { Analysis: service area analysis, network analysis, geographical weighted } \\
\text { regression. Cluster analysis. }\end{array}$ \\
\hline & Behavioural & $\begin{array}{l}\text { Frequency and preference of transportation modes for different activities } \\
\text { (commuting, shopping, leisure) }\end{array}$ \\
\hline & Perceptual & $\begin{array}{l}\text { Differences between reported (perceived) and actual closeness to services and } \\
\text { activities. Perceived advantages and disadvantages of each transportation mode. }\end{array}$ \\
\hline \multirow{3}{*}{$\begin{array}{l}\text { What are the differences } \\
\text { between people who would } \\
\text { change from motorized } \\
\text { mobility and people who } \\
\text { would not? }\end{array}$} & Methodological & $\begin{array}{l}\text { Data collection: survey on households, secondary sources. } \\
\text { Analysis: MCA }\end{array}$ \\
\hline & Behavioural & Demographics and geographic characteristics of each group of households. \\
\hline & Perceptual & Perceived attributes of each transportation mode of each group. \\
\hline
\end{tabular}

Table 1. Example of implementation of the proposed framework for the study of mobility patterns of pedestrians and bicyclists.

\section{ACKNOWLEDGEMENTS}

This work is part of the project "Pies y Pedales, estudio de los patrones de movilidad de ciclistas y peatones para una movilidad sustentable", supported by the Research Directorate DIUC of Universidad of Cuenca. The authors wish to thank the members of LlactaLAB - Ciudades Sustentables Research Group of the Department of Space and Population of Universidad de Cuenca for their contribution.

\section{REFERENCES}

Aldred, R. (2010). 'On the outside': constructing cycling citizenship. Social \& Cultural Geography, 11(1), 35-52. doi:10.1080/14649360903414593

Aldred, R. (2013). Incompetent or Too Competent? Negotiating Everyday Cycling Identities in a Motor Dominated Society. Mobilities, 8(2), 252-271. doi:10.1080/17450101.2012.696342

Alfonzo, M. (2005). To walk or not to walk. Environment and Behaviour, 161(18), 30. doi:10.1177/0013916504274016

Alfonzo, M., Boarnet, M. G., Day, K., Mcmillan, T., and Anderson, C. L. (2006). The Relationship of Neighborhood Built Environment Features and Walking. University of California Transportation Center.

Alvares, L. O., Bogorny, V., Kuijpers, B., Macedo, J., Moelans, B., and Vaisman, A. A. (2007). A model for enriching trajectories with semantic geographical information. In $\mathrm{H}$. Samet \& S.-L. Shaw (Eds.), Proceedings of the 15th annual ACM international symposium on Advances in geographic information systems (pp. 162-169). New York: ACM.
Andrienko, G., and Andrienko, N. (2008). A Visual Analytics Approach to Exploration of Large Amounts of Movement Data. In M. Sebillo, G. Vitiello, \& G. Schaefer (Eds.), Visual Information Systems, 10th International Conference, VISUAL 2008 (pp. 1-4). Springer-Berlin.

Baglioni, M., Macedo, J., Renso, C., Trasarti, R., and Wachowicz, M. (2009). Towards a semantic interpretation of movement behaviour. In Proceedings of AGILE 2009 (To appear).

Barrero, L. H., Quintana, L. A., Sánchez, A., Forero, A., Quiroga, J., and Felknor, S. (2013). Pedestrians' beliefs about road crossing in bogotá: Questionnaire development. Universitas Psychologica, 12(2), 433-444.

Bernhoft, I. M., and Carstensen, G. (2008). Preferences and behaviour of pedestrians and cyclists by age and gender. Transportation Research Part F: Traffic Psychology and Behaviour, 11(2), 83-95. doi:10.1016/j.trf.2007.08.004

Bogorny, V., Heuser, C., and Alvares, L. O. (2010). A Conceptual Data Model for Trajectory Data Mining. In S. I. Fabrikant, T. Reichenbacher, M. Van Kreveld, \& C. Schlieder (Eds.), Geographic Information Science. 6th International Conference, GIScience 2010 (Vol. 6292, pp. 1-15). Springer. doi:10.1007/978-3-642-15300-6

Capos SpA. (2015). KAPPO - Urban Cyclists's Behaviour Study. Retrieved 6 August 2015, from http://www.kappo.bike/mtt-report/index_en.html\#

Cervero, R., Sarmiento, O. L., Jacoby, E., Gomez, L. F., and Neiman, A. (2009). Influences of Built Environments on Walking and Cycling: Lessons from Bogotá. International 
Journal of Sustainable Transportation, 3(4), 203-226. doi:10.1080/15568310802178314

Dunkel, A. (2015). Visualizing the perceived environment using crowdsourced photo geodata. Landscape and Urban Planning. doi:10.1016/j.landurbplan.2015.02.022

Duppen, J. Van, and Spierings, B. (2013). Retracing trajectories : the embodied experience of cycling , urban sensescapes and the commute between ' neighbourhood' and ' city ' in Utrecht, NL. Journal of Transport Geography, 30, 234-243. doi:10.1016/j.jtrangeo.2013.02.006

Feng, T., and Timmermans, H. J. P. (2014). Extracting Activitytravel Diaries from GPS Data: Towards Integrated Semiautomatic Imputation. Procedia Environmental Sciences, 22, 178-185. doi:10.1016/j.proenv.2014.11.018

Forlizzi, L., Güting, R. H., Nardelli, E., and Schneider, M. (2000). A data model and data structures for moving objects databases. In Proceedings of the 2000 ACM SIGMOD international conference on Management of data (pp. 319-330). ACM New York, NY, USA

Golob, T. T., and Meurs, H. (1986). Biases in response over time in a seven-day travel diary. Transportation, 13(2), 163181. doi:10.1007/BF00165546

Google. (2016). Google Maps. Retrieved from http://maps.google.com/

Green, J., Steinbach, R., Datta, J., and Edwards, P. (2010). Cycling in London: a study of social and cultural factors in transport mode choice. London: LSHTM.

Griffin, G., and Jiao, J. (n.d.). Crowdsourcing Bicycle Volumes : Exploring the role of volunteered geographic information and established monitoring methods. Compendium of Transportation Research Board Annual Meeting, 1-19.

Griffin, G. P., and Jiao, J. (2015). Where does Bicycling for Health Happen? Analysing Volunteered Geographic Information through Place and Plexus. Journal of Transport \& Health. doi:10.1016/j.jth.2014.12.001

Gudmundsson, J., Laube, P., and Wolle, T. (2007). Movement patterns in spatio-temporal data. In S. Shekhar \& H. Xiong (Eds.), Encyclopedia of GIS (pp. 726-732). New York: Springer-Verlag.

Güting, R. H., and Schneider, M. (2005). Moving Objects Databases. London: Morgan Kaufmann.

Hägerstrand, T. (1970). What about people in Regional Science? Papers in Regional Science, 24(1), 6-21.

Handy, S. L., and Xing, Y. (2011a). Factors Correlated with Bicycle Commuting: A Study in Six Small U.S. Cities. International Journal of Sustainable Transportation, 5(2), 91110.

Handy, S. L., and Xing, Y. (2011b). Factors Correlated with Bicycle Commuting: A Study in Six Small U.S. Cities. International Journal of Sustainable Transportation, 5(2), 91110. doi:10.1080/15568310903514789

Heinen, E., van Wee, B., and Maat, K. (2010). Commuting by Bicycle: An Overview of the Literature. Transport Reviews, 30(1), 59-96. doi:10.1080/01441640903187001

Hillier, B. (2007). Space is the machine. London: Space Syntax Ltd.

Hoogendoorn, S. P., and Bovy, P. H. L. (2004). Pedestrian route-choice and activity scheduling theory and models. Transportation Research Part B, 38(2), 169-190.
Iseki, H., and Tingstrom, M. (2014). A new approach for bikeshed analysis with consideration of topography, street connectivity, and energy consumption. Computers, Environment and Urban Systems, 48, 166-177.

Jirón, P. (2011). On becoming 'la sombra/the shadow'. In M. Buscher, J. Urry, \& K. Witchger (Eds.), Mobile Methods (pp. 36-53). New York: Routledge.

Jones, P. (2005). Performing the city: a body and a bicycle take on Birmingham, UK. Social \& Cultural Geography, 6(6), 813830. doi:10.1080/14649360500353046

Jones, T., Pooley, C. G., Scheldeman, G., Horton, D., Tight, M., Mullen, C., ... Whiteing, A. (2012). Moving around the city: Discourses on walking and cycling in english urban areas. Environment and Planning A, 44(6), 1407-1424. doi:10.1068/a44387

Jungnickel, K., and Aldred, R. (2014). Cycling's Sensory Strategies: How Cyclists Mediate their Exposure to the Urban Environment. Mobilities, 9(2), 238-255. doi:10.1080/17450101.2013.796772

Kaparias, I., Bell, M. G. H., Miri, A., Chan, C., and Mount, B. (2012). Analysing the perceptions of pedestrians and drivers to shared space. Transportation Research Part F: Psychology and Behaviour, 15(3), 297-310. doi:10.1016/j.trf.2012.02.001

Khan, M., Kockelman, K. M., and Xiong, X. (2014). Models for anticipating non-motorized travel choices, and the role of the built environment. Transport Policy, 35, 117-126. doi:10.1016/j.tranpol.2014.05.008

Laube, P. (2009). Progress in Movement Pattern Analysis. In B. Gottfried \& H. K. Aghajan (Eds.), Behaviour Monitoring and Interpretation - Smart Environments (Vol. 3, pp. 43-71). Amsterdam: IOS Press BV.

Lugo, A. E. (2013). CicLAvia and human infrastructure in Los Angeles: ethnographic experiments in equitable bike planning. Journal of Transport Geography, 30, 202-207.

Manum, B., and Nordstrom, T. (2013). Integrating Bicycle Network Analysis in Urban Design: Improving bikeability in Trondheim by combining space syntax and GIS-methods using the place syntax tool. In Y. O. Kim, H. T. Park, \& K. W. Seo (Eds.), Proceedings of the Ninth International Space Syntax Symposium. Sejong University.

Mayer-Kress, G., Liu, Y.-T., and Newell, K. M. (2006). Complex systems and human movement. Complexity, 12(2), 40-51. doi:10.1002/cplx.20151

McMillan, D. W., and Chavis, D. M. (1986). Sense of community: A definition and theory. Journal of Community Psychology, 14(1), 6-23. doi:10.1002/15206629(198601)14:1<6::AID-JCOP2290140103>3.0.CO;2-I

Mehta, V. (2008). Walkable streets: pedestrian behavior, perceptions and attitudes. Journal of Urbanism: International Research on Placemaking and Urban Sustainability, 1(3), 217245. doi:10.1080/17549170802529480

Meneses-Reyes, R. (2013). Law and Mobility : Ethnographical Accounts of the Regulation of the Segregated Cycle Facilities in Mexico City. Mobilities, (February 2015), 37-41. doi:10.1080/17450101.2013.853388

Orellana, D., and Renso, C. (2010). Developing an Interactions Ontology for Characterising Pedestrian Movement. In M. Wachowicz (Ed.), Movement-Aware Aplications for Sustainable Mobility (Vol. 1, pp. 62-86). New York: Information Science Reference. 
Orellana, D., and Wachowicz, M. (2011). Exploring Patterns of Movement Suspension in Pedestrian Mobility. Geographical Analysis, 43(3), 241-260. doi:10.1111/j.15384632.2011.00818.x

Quercia, D., Schifanella, R., and Aiello, L. M. (2014). The shortest path to happiness. In Proceedings of the 25th ACM conference on Hypertext and social media - HT '14 (pp. 116125). New York, New York, USA: ACM Press. doi:10.1145/2631775.2631799

Quiroga, J., Romero, N., García, C., and Parra, C. (2011). Adquisición de variables de tráfico peatonal utilizando visión por computador. Revista Facultad de Ingenieria, (60), 51-61.

Raford, N., Chiaradia, A. J., and Gil, J. (2007). Space Syntax: The Role of Urban Form in Cyclist Route Choice in Central London. SafeTrec Research Reports, 18.

Rodríguez, D., and Joo, J. (2004). The relationship between non-motorized mode choice and the local physical environment. Transportation Research Part D: Transport and Environment, 9(2), 151-173. doi:10.1016/j.trd.2003.11.001

Rybarczyk, G., and Wu, C. (2010). Bicycle facility planning using GIS and multi-criteria decision analysis. Applied Geography, 30(2), 282-293. doi:10.1016/j.apgeog.2009.08.005

Saelens, B. E., Sallis, J. F., and Frank, L. D. (2003).

Environmental correlates of walking and cycling: Findings from the transportation, urban design, and planning literatures.

Annals of Behavioral Medicine, 25(2), 80-91.

doi:10.1207/S15324796ABM2502_03

Sayed, T., Zaki, M. H., and Autey, J. (2013). Automated safety diagnosis of vehicle-bicycle interactions using computer vision analysis. Safety Science, 59, 163-172.

doi:10.1016/j.ssci.2013.05.009

Skinner, D., and Rosen, P. (2007). Hell is other cyclists: rethinking transport and identity. In P. Rosen, P. Cox, \& D. Horton (Eds.), Cycling and society (pp. 83-96). Ashgate Aldershot.

Spinney, J. (2011). A chance to catch a breath: using mobile video ethnography in cycling research. Mobilities, 6(2), 161182. doi:10.1080/17450101.2011.552771

Talavera-Garcia, R., and Soria-Lara, J. (2015). Q-PLOS, developing an alternative walking index. A method based on urban design quality. Cities, 45, 7-17.

doi:10.1016/j.cities.2015.03.003

Thomas, J. J., and Cook, K. A. (2006). A visual analytics agenda. Computer Graphics and Applications, IEEE, 26(1), 1013.

Thomason, A., Griffiths, N., and Sanchez, V. (2015). Identifying locations from geospatial trajectories. Journal of Computer and System Sciences. doi:10.1016/j.jcss.2015.10.005

Torres, Y. Q. A., and Costa, L. M. S. A. (2014). Digital Narratives: Mapping Contemporary Use of Urban Open Spaces through Geo-social Data. Procedia Environmental Sciences, 22, 1-11. doi:10.1016/j.proenv.2014.11.001

Tryfona, N., and Jensen, C. S. (1999). Conceptual Data Modeling for Spatiotemporal Applications. GeoInformatica, 3(3), 245-268.

Victoria Transport Policy Institute. (2016). Online TDM Encyclopedia. Retrieved 2 April 2016, from http://www.vtpi.org/tdm/

Waze Mobile. (2016). Waze. Retrieved 2 April 2016, from https://www.waze.com/about
Weinstein Agrawal, A., Schlossberg, M., and Irvin, K. (2008). How Far, by Which Route and Why? A Spatial Analysis of Pedestrian Preference. Journal of Urban Design, 13(1), 81-98. doi:10.1080/13574800701804074

Wiener, J. M., Büchner, S. J., and Hölscher, C. (2009).

Taxonomy of Human Wayfinding Tasks: A Knowledge-Based Approach. Spatial Cognition \& Computation, 9(2), 152-165. doi:10.1080/13875860902906496

Wood, L., Frank, L. D., and Giles-Corti, B. (2010). Sense of community and its relationship with walking and neighborhood design. Social Science and Medicine, 70(9), 1381-1390. doi:10.1016/j.socscimed.2010.01.021

Zaki, M. H., and Sayed, T. (2013). A framework for automated road-users classification using movement trajectories.

Transportation Research Part C: Emerging Technologies, 33, 50-73. doi:10.1016/j.trc.2013.04.007 